DOI 10.37882/2500-3682.2020.09.12

\title{
ЭКЗИСТЕНЦИАЛЬНАЯ ИСПОЛНЕННОСТЬ И ЕЕ ВЗАИМОСВЯЗЬ С БЛАГОПРИЯТНЫМ ПРОФИЛЕМ ЛИЧНОСТНЫХ ХАРАКТЕРИСТИК
}

\section{THE EXISTENTIAL FULLFILLMENT AND THE FAVOURABLE PERSONAL CHARACTERISTIS}

A. Lito

A. Litvinenko

Summary: The goal of this study was to explore the level of existential fulfillment and the individual characteristics and association between them. Specifically, we explored the existential fulfillment as the existential equivalent of the happiness from one side and neuroticism, aggression, anxiety, openness, strain, emotional stability, from the other side for six years (2012 and 2018). Participants were $n=173$ ( 89 women and 84 men); they filled two types of questionnaires both times. The level of existential fulfillment was higher for the favorable level of individual characteristics.

Keywords: self-distance, lifespan, self-transcendence, freedom, responsibility, existential fulfillment, neuroticism, aggression, anxiety, opennes, strain, emotional stability, social orientation.
Лито Адриана Николаевна

Независимый исследователь

adrianaimj7@gmail.com

Литвиненко Анастасия Николаевна

Независимый исследователь anlipsi@yandex.ru

Аннотация: Целью этого исследования было рассмотреть такой параметр как экзистенциальная исполненность по В. Франклу в связи с некоторыми личностными характеристиками и оценить их взаимодействие.

Экзистенциальная исполенность в данном случае рассматривается как экзистенциальный аналог счастья. Для оценки профиля личностных характеристик мы рассматривали следующие факторы: склонность к неврозу, агрессию, тревогу, открытость, упрямство, эмоциональную стабильность. Исследование проводилось в течение шести лет (с 2012 по 2018 годы). Участниками были 173 испытуемых (89 мужчин и 84 женщины).

Участники в ходе исследования заполняли два опросника дважды.

Предварительно можно сказать, что чем более благоприятен личностный профиль, тем более высокий уровень экзистенциальной исполеннности показывали участники исследования.

Ключевые слова: самотрансценденция, жизненный путь личности, самодистацирование, свобода, ответственность, экзистенциальная исполненность, невротичность, агрессия, тревога, открытость, общительность, упрямство, эмоциональная стабильность.

Исследователи поздних кризисов, настигающих человека после сорока, также говорят о том, что личные качества важны: люди, лучше справляющиеся с ним обычно более открыты к новому опыту и показывают низкий уровень склонности к неврозу и тревоге [2].

Личностный рост - это сложный и противоречивый процесс, который содержит в себе множество обстоятельств. Эти противоречия рождаются из сложной натуры человека. Значительным обстоятельством такого противоречия является взаимодействия желания любить и быть замеченным другими людьми и одновременным желанием реализоваться. Личностное развитие требует постоянного изменения и переоценки собственного опыта на каждой стадии.

В результате человек постоянно находится в дуализмe:

1. Сравнивает и принимает себя, свою индивидуальность, характер - потому что только так он может найти свободу и независимость;

2. Ищет собственное место в жизни среди других людей, потому что только так можно найти лю- 
бовь и поддержку;

3. Пониамет ценности и смысл своей жизни и своей миссии, принимая ответственность за свои цели и личностный рост;

4. Понимает механизмы, которые направляют его развитие;

5. Движется в русле настоящей жизни;

6. Защищает собственное я от проекций, замен и отвлечений, следующих из социального давления для обретения внутреннего мира и покоя [11].

\section{1. Экзистеншиальная исполненность}

Экзистенциальная исполненность - это термин, введенный Виктором Франклом [9]. Описывает качество человеческой жизни как некоторое противопоставление обычном счастью. Исполенность - это счастье как смысл, но не как гедонистическая концепция, счастье через действие по Аристотелю.

Уровень экзистенциальной исполненности показывает, насколько часто личность реализует собственные желания и действует в соответствии собственной идентичности.

Для того, чтобы объяснить, что такое благоприятный профиль личности по опроснику FPI, нам необходимо перечислить входящие в него индивиуальные характеристики [9]:

1. Невротичность: ипохондрия, проблемы со здоровьем и саморегуляцией, склонности к неврозу и тревоге. Высокий уровень - 7-9 баллов, низкий уровень 1-4 - показывает спокойствие.

2. Спонтанная агрессия - уровень психопатизации, склонность «взрываться». Благоприятный уровень - 4-6.

3. Депрессия - склонность к депрессии. Высокий уровень (7-9) показывает высокую чувствительность к стрессу, благоприятный уровень 1-6.

4. Раздражительность: высокий уровень означает сложности с контактом (7-9). Благоприятный уровень (1-5)

5. Общительность. Высокий уровень показывает хороший контакт с людьми (6-9). Низкий уровень изоляция(1-4).

6. Уравновешенность: высокий уровень показывает оптимизм и самоподдержку (6-9). Низкий уровень - нестабильность (1-4).

7. Упрямство. Высокий уровень показывает низкий уровень эмпатии (7-9). Низкий уровень - конформизм. Благоприятный уровень - (5-7).

8. Стеснительность. Высокий уровень (7-9) предполагает тревогу и низкую самооценкую. Благоприятный уровень (1-6).

9. Эмоциональная нестабильность - высокий уровень означает невозможность саморегуляции.

\section{Благоприятный уровень 1-7.}

Таким образом мы составили список благоприятных качеств: шкалы I (1-4), II (4-7), III (1-6), IV (1-5), VI (6-9), VII (1-7), VIII (1-7), IX (6-9) и XI (1-7).

\section{2.Методы}

\section{1. Участники исследования}

Первая часть исследования происходила в 2012 году. В тот моменты мы опросили более 395 человек от 25 до 40 лет, проживавших в крупных городах России (Москва, Санкт-Петербург и т.д.). В исследовании приняли участие 199 женщин и 196 мужчин. В результате мы получили 395 заполненных анкеты. Все участники были проинформированы о целях и идеях исследования.

Шесть лет спустя (в 2018 году) мы связались с нашими участниками с помощью рассылки информации на электронные адреса и попросили снова заполнить те же самые опросники. В результате мы получили 173 заполненных опросника (89 женщин и 84 мужчины). Для сравнения мы использовали именно эти 173 опросника.

Каждый участник в исследовании получал собственный уникальный номер, поэтому данные не могли быть спутаны или скомпрометированы.

\section{2.Прочехура}

Исследование включало в себя три части:

1. Создание выборки (описано выше)

2. Заполнение опросников в 2012-2013

3. Заполнение опросников в 2018

\section{3.Инструменты}

Для исследования мы использовали следующие опросники:

1. FPI - Фрайбургский личностный опросник (Фаренберг и другие, 2008). Он состоит из 138 опросников, который изменяет следующий список личностных черт: невротичность, спонтанная агрессивность, депрессивность, раздражительность, общительность, уравновешенность, реактивная агрессивность, застенчивость, эмоциональную лабильность и открытость (а также маскулинность, феминность и экстраверсию-интраверсию).

2. Шкала экзистенции Лэнгли-Орглер. Это личностный опросник для измерения экзистенциальной исполенности личности. Базируется на теории Франкла и четырех фундаментальных мотивациях личности Лэнгле. Включает в себя 46 вопросв и четыре суб-шкалы: самодистанцирование, са- 
мотрансценденцию, ответственности и свободу, которые складываются в шкалы личность и экзистенция, сумма которых дает итоговый балл теста - экзистенциальную исполенность.

\section{4.Статистическая процедура}

Для подсчета и обработки данных мы использовали программу SPSS. Также мы обработали полученные данные, чтобы соотносить не только корреляцию отдельных шкал, но и совпадение ответов у одних и тех же испытуемых.

\section{3.Результаты}

Исследование проводилось в два этапа.
Первый — в 2012-2013 году

Мы разделили ответы наших испытуемых на три группы в зависимости от благоприятности уровня FPI (этот уровень в группе варьировался от 8 до 63, и мы использовали уровень от 43 до 63, от 23 до 43 и от 8 до 23).

Далее мы рассмотрим значения этого коэффициента для разных групп испытуемых по уровню благоприятности FPI:

Первая группа - с высоким уровнем благоприятности FPI (ответы с благоприятностью от 43 до 63) - уровень ЭИ (экзистенциальной исполненности) для этой группы варьировался от 183 до 234, медиана и среднее - 207. Количество испытуемых в группе было 63 (Таблица 1).

Уровень ЭИ для благоприятных индивидуальных характеристик FPI (2012)

Таблица 1.

\section{Уровень ЭИ в группе с благоприятным FPI 2012} ОХ - кол-во испытуемых, ОY - ЭИ

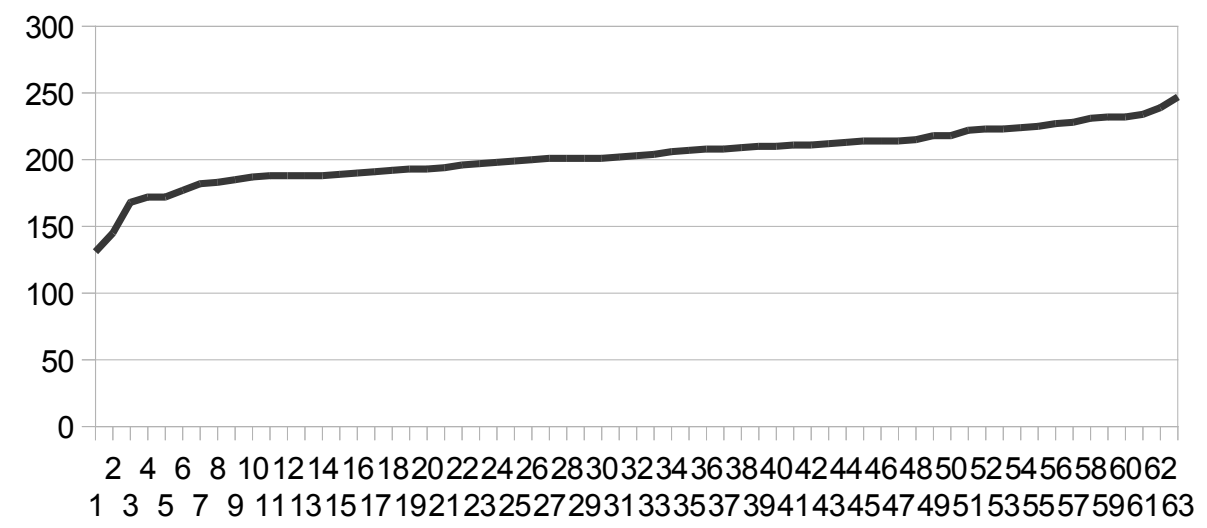

Уровень ЭИ для среднего уровня индивидуальных характеристик FPI (2012)

Таблица 2

\section{Уровень ЭИ для среднего уровня FPI (2012) ОХ - кол-во испытуемых, ОҮ - уровень ЭИ}

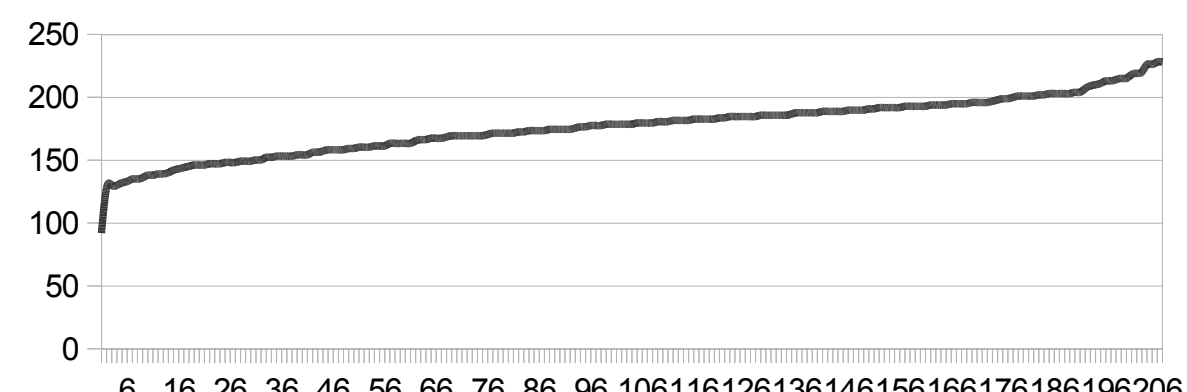

$6 \quad 1626 \quad 364656 \quad 66 \quad 76 \quad 8696106116126136146156166176186196206$ 1112131415161718191101111121131141151161171181191201 
Во второй группе со уровнем благоприятности FPI от 23 до 43, оказалось 207 испытуемых. Уровень Экзистенциальной исполненности варьировался от 92 до 227, среднее 176 и медиана 178 (Таблица 2).

Для третьей группы уровень FPI варьировался от 8 до 23, в ней оказалось 125 испытуемых. Уровень экзистенциальной исполенности от 85 до 208, среднее 156 и медиана 156 (Таблица 3).

Как мы видим для 365 испытуемых, корреляция между индивидуальными характеристиками и экзистенциальной исполненности очевидна: менее благоприятные коэффициенты FPI соотносятся с менее благоприятным уровнем экзистенциальной исполеннности.

Вторая часть: 2018
Мы повторили свое исследование в 2018. Мы сравнили высокие и низкие показатели: в этот раз из 365 испытуемых в исследовании приняли участие 174, наиболее высокий уровень благоприятности FPI был 64, самый никзий -9.

Мы можем проследить и три благоприятных группы:

Первая группа - это уровень благоприятности FPI от 43 до 64. В эту группу вошло 35 испытуемых, коэффициент ЭИ варьировался от 169 до 234, среднее 207, медиана - 210 (Таблица 4).

Вторая группа с уровнем FPI 23-43 была представлена 97 испытуемыми, коэффициент ЭИ варьировался от 110 до 227, среднее 175, медиана 174 (Таблица 5).

Уровень ЭИ для низкого уровня индивидуальных характеристик FPI (2012)

Таблица 3.

Уровень ЭИ для низкого значения FPI (2012) OX - кол-во испытуемых, OY - ЭИ

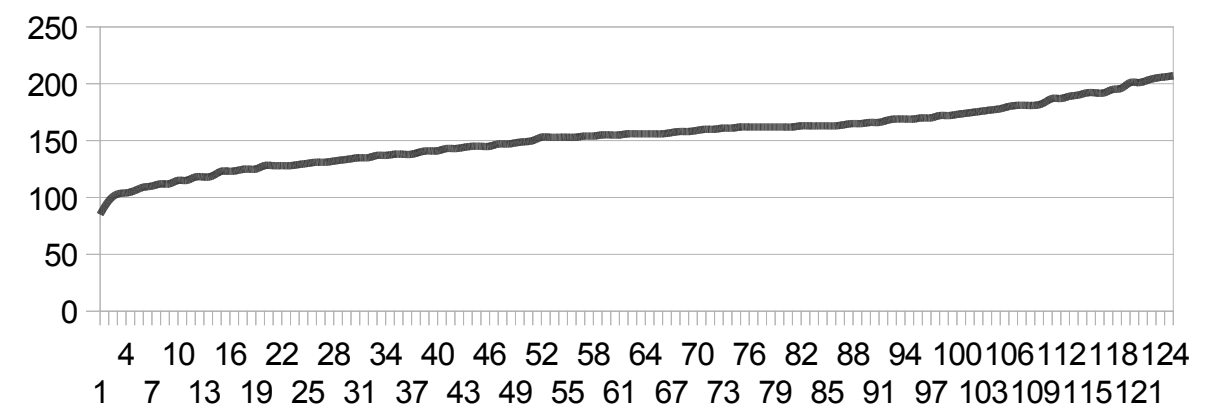

Таблица 4

Уровень экзистенциально исполненности для высокого уровня благоприятности FPI (2018)

Уровень ЭИ для благоприятного уровня FPI (2018) ОХ - кол-во испытуемых, ОY - уровень ЭИ

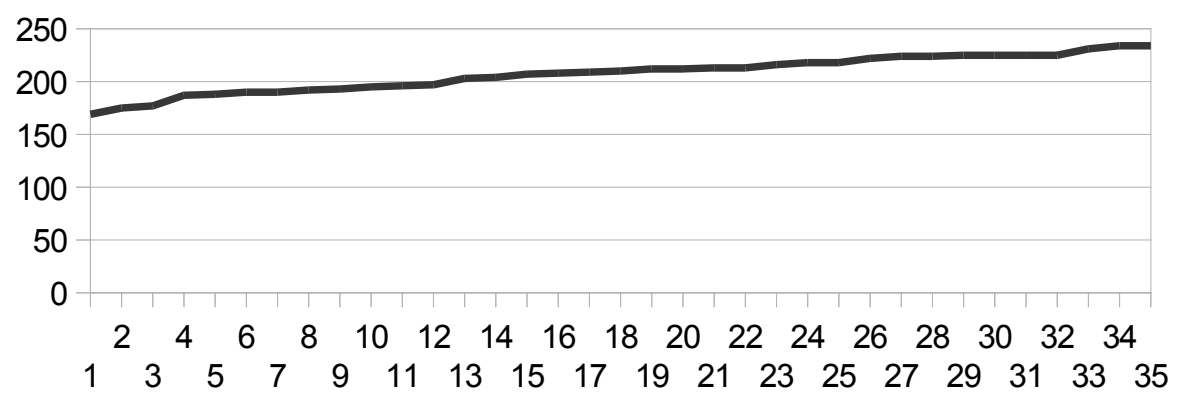


Уровень корреляции экзистенциальной исполненности со средним уровнем FPI (2018)

Уровень экзистенциальной исполенности для среднего FPI (2018) OХ - количество испытуемых, ОY - уровень ЭИ

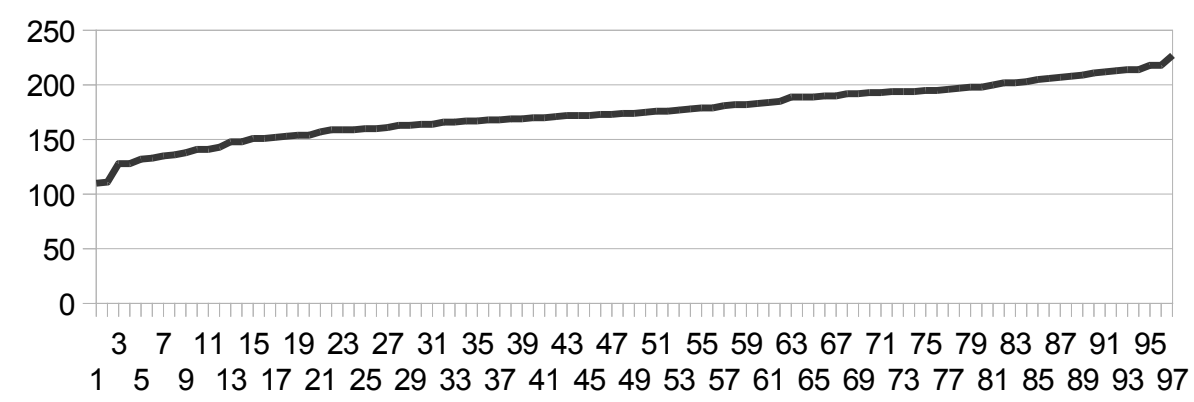

Уровень экзистенциальной исполенности для низкого уровня благоприятности FPI (2018)

Таблица 6

Уровень ЭИ для низкого уровня благоприятности ЭИ (2018) ОХ - кол-во испытуемых, ОY - Уровень ЭИ

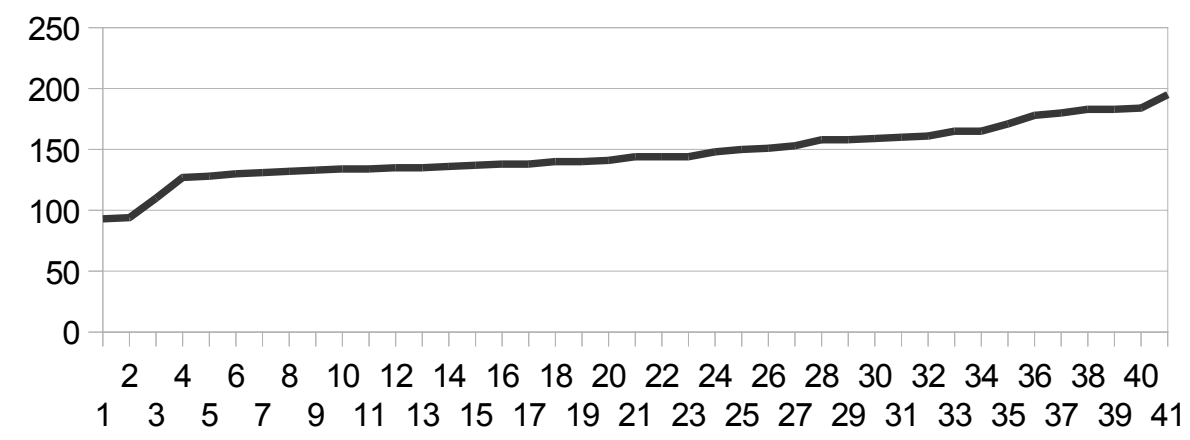

Таблица 7

Таблица 8

Корреляция уровня благоприятности FPI и шкал FPI (2013 и 2018)

\begin{tabular}{|l|l|l|}
\hline Шкала & $\begin{array}{l}\text { Коэфф. Кор. } \\
2013\end{array}$ & $\begin{array}{l}\text { Коэфф.Кор } \\
2018\end{array}$ \\
\hline 1. Невротичность & $-0,73$ & $-0,73$ \\
\hline 2. Спонтанная агрессивность & $-0,43$ & $-0,43$ \\
\hline 3. Депрессия & $-0,86$ & $-0,91$ \\
\hline 4. Раздражительность & $-0,62$ & $-0,71$ \\
\hline 5. Общительность & 0,53 & 0,58 \\
\hline 6. Уравновешенность & 0,62 & 0,72 \\
\hline 7. Упрямство & $-0,34$ & 0,34 \\
\hline 8. Застенчивость & 0,72 & $-0,72$ \\
\hline 11. Эмоциональная нестабильность & $-0,88$ & $-0,9$ \\
\hline
\end{tabular}

Корреляция уровня благоприятности FPI и шкал опросника Лэнгле-Оглер

\begin{tabular}{|l|l|l|}
\hline Шкала & $\begin{array}{l}\text { Коэфф. } \\
\text { Кор. 2013 }\end{array}$ & $\begin{array}{l}\text { Коэфф. } \\
\text { Кор. 2013 }\end{array}$ \\
\hline Самодистанцирование & 0,42 & 0,33 \\
\hline Самотрансценденция & 0,53 & 0,62 \\
\hline Свобода & 0,55 & 0,56 \\
\hline Ответственность & 0,59 & 0,64 \\
\hline Личность & 0,58 & 0,61 \\
\hline Экзистенция & 0,61 & 0,63 \\
\hline Экзистенциальная исполенность & 0,65 & 0,71 \\
\hline
\end{tabular}


Третья группа с низким уровнем FPI от 9 до 23 была представлена 41 испытуемым, уровень экзистенциальной исполеннности варьировался от 93 до 201, среднее 146, медиана 144 (Таблица 6).

Мы также провели оценку корреляций благоприятного уровня FPI со шкалами FPI и шкалами опросника Лэнгли-Оглер (Таблицы 7, 8).

Как мы видим, этот показатель показывает высокую значимую корреляцию с благоприятными шкалами, отрицательную - с неблагоприятными и высокую значимую корреляцию с экзистенциальными аспектами опросника Лэнгле-Оглер. Также мы видим, что, спустя 6 лет, тенденция в данной группе сохранилась.

\section{$\Delta$ искуссия}

Конечно, это не первое исследование: есть целый ряд работ на тему отношений личностных характеристик с последствиями для личности, например, корреляция личных качеств детей с их успехами и трудностями в дальнейшей жизни (как мы уже писали), а также - например, с такими ценными качествами, как родительские стратегии: мы знаем, что люди с высоким уровнем открытости и способности договариваться чаще выбирают авторитетное и демократическое родительство, а люди с невротичностью - нестабильное или невовлеченное родительство (Eisenberg et al, 2006, Durkin, 1995). Наше исследование было посвящено новому пласту исследованию отношений личностных характеристик с экзистенциальными аспектами личности.

Как мы видим, и в 2012, и в 2018 году, есть значимая корреляция между уровнем благоприятности FPI и уровнем экзистенциальной исполеннности у испытуемых. Мы можем сказать, что индивидуальные характеристики личности и экзистенциальные аспекты связаны, поэтому личность с низким уровнем невротичности, депрессии, спонтанной агрессии, эмоциональной нестабильности и упрямства, а также с высоким уровнем общительности и уравновешенности будет более счастлива и реализована в мире.

\section{ЛИТЕРАТУРА}

1. Clark, L.A., Kochanska, G., \& Ready, R. (2000). Mothers' personality and its interaction with child temperament as predictors of parenting behavior. Journal of Personality and Social Psychology, 79, 274-285.

2. de St. Aubin, E., \& Mc Adams, D. P. (1995). The relation of generative concern and generative action to personality traits, satisfaction/happiness with life and ego development. Journal of Adult Development, 2, 99-112.

3. Durkin K. "Developmental social psychology: from infancy to old age". Blackwell Publishnig 1995

4. Eisenberg, N., Fabes, R.A., \& Spinrad, T.L. (2006). Prosocial development. In R.M. Lerner, N. Eisenberg, \& W. Damon (Eds.). Handbook of child psychology: Vol. 3. Social, emotional and personality development (pp. 646ᄀ718). New York: Wiley.

5. Eisenberg, N., Fabes, R.A., Shepard, S.A., Guthrie, I.K., Murphy, B.C., \& Reiser, M. (1999). Parental reactions to children's negative emotions: Longitudinal relations to quality of children's social functioning. Child Development, 70, 513-534.

6. Eisenberg, N., Hofer, C., Spinrad, T.L., Gershoff, E.T., Valiente, C., Losoya, S., Maxon, E. (2008). Understanding mother-adolescent conflict discussions: Concurrent and across-time prediction from youths' dispositions and parenting. Monographs of the Society for Research in Child Development, 73, 1-160.

7. Erik H. Erikson, Joan M. Erikson, The Life Cycle Completed: Extended Version (W. W. Norton, 1998)

8. Fahrenberg J., Hampel R., Selg H.: FPI-R Freiburger Persönlichkeitsinventar. 8. erweiterte Aufl. Hogrefe, Göttingen 2010.

9. FrankI V. "Happiness and the meaning of life". Krankenpflege Journal. 32:427-8, Wurzburg, Berlin 1994

10. Kiff, C.J., Lengua, L.J., \& Zalewski, M. (2011). Nature and nurturing: Parenting in the context of child temperament. Clinical Child and Family Psychology Review, 14, 251-301. doi: 10.1007/s10567011-0093-4

11. Langely A (2004) Objectives of Existential Psychology and Existential Psychotherapy. In:International Journal of Existential Psychology and Psychotherapy 1, 1,99102

12. Peterson, B.E., Smirles, K. A., \& Wentworth, P.A. (1997). Generativity and authoritarianism: Implications for personality, political involvement, and parenting. Journal of Personality and Social Psychology, 72, 1202-1216.

( ) Лито Адриана Николаевна (adrianaimj7@gmail.com), Литвиненко Анастасия Николаевна (anlipsi@yandex.ru).

Журнал «Современная наука: актуальные проблемы теории и практики» 